Brazilian Journal
of Chemical
Engineering

ISSN 0104-6632

Printed in Brazil

www.abeq.org.br/bjche

Vol. 25, No. 03, pp. 523 - 534, July - September, 2008

\title{
POLYMER SOLUTION AND LATTICE THEORY APPLICATIONS FOR MODELING OF ASPHALTENE PRECIPITATION IN PETROLEUM MIXTURES
}

\author{
S. A. Mousavi-Dehghani ${ }^{1 *}$, B. Mirzayi ${ }^{2}$ and M. Vafaie-Sefti ${ }^{3}$ \\ ${ }^{1}$ Research Institute of Petroleum Industry, NIOC, RIPI, \\ Phone/Fax: +(98) (21) 44739541, P.O. Box: 18745-4163, Tehran, Iran. \\ E-mail: mousavisa@ripi.ir \\ ${ }^{2}$ Department of Chemical Engineering, Mohaghegh Ardabili University, Ardabil, Iran. \\ ${ }^{3}$ Department of Chemical Engineering, Tarbiat-Modarress University, \\ P.O. Box 14115-4838, Tehran, Iran.
}

(Received: February 2, 2007 ; Accepted: March 15, 2008)

\begin{abstract}
Here asphaltene precipitation in petroleum reservoirs during natural depletion and miscible gas injection is modeled via two distinct and new methods (polymer solution and lattice theories). The first model is based on the polymer solution theory, which is a combination of Miller's combinatorial term with a modified residual term of the original Flory-Huggins theory. The second one is the application of the wellknown Sanchez-Lacombe equation of state (SL EOS) to describe the phase behavior of asphaltene compounds in crude oil. The results of both models show an acceptable and good agreement between the real data (field and experimental) and these two models. As it can be seen from the obtained results of these two models, it seems application of the lattice or polymer solution theories (based on The Miller's combinatorial term) could give the better and more close to real data.

Keywords: Asphaltene; Polymer solution; SL EOS; Petroleum mixtures, Precipitation.
\end{abstract}

\section{INTRODUCTION}

Asphaltenes are polar compounds that are stabilized in crude oil by peptizing agent such as resins in crude oils. Asphaltene is referred to the fraction of crude oil insoluble in excess normal alkanes such as n-pentane or n-heptane, but soluble in benzene or toluene under ambient conditions; while resins are the fraction of crude oil insoluble in liquid propane but soluble in n-pentane at ambient conditions. The chemical structures and physicochemical properties of asphaltenes are not well understood. However, NMR and infraredspectroscopic data show that asphaltene molecules contain condensed polynuclear aromatic rings with alkyl side chains and heteroatoms such as $\mathrm{N}, \mathrm{O}, \mathrm{S}$ and Ni (Speight, 1991; Mousavi et al., 2004). Other experimental data suggest that asphaltene molecules can associate even at very small concentrations in most solvents (Speight, 1994; Sheu et al., 1992a; Andersen and Birdil, 1991; Andersen and Spight, 1993). Asphaltene association may be due to hydrogen bonding and/or formation of chargetransfer complexes. Asphaltenes can be subfractionated into bases, acids, and neutral polar components by ion-exchange or high pressure liquid chromatography (HPLC) (Mushrush and Speight, 1995).

In this work, the polymeric nature of asphaltene compounds in petroleum mixtures is applied in

*To whom correspondence should be addressed 
thermodynamic modeling of asphaltene precipitation via two distinct methods. At the first model, modifications are made in the enthalpy and entropy terms of the Flory-Huggins (FH) theory. The enthalpy (residual) term in the FH theory is improved by adding the interaction parameter and modifying the entropy (combinatorial) term by the Miller equation. Here, this modified FH theory $(\mathrm{MFH})$ is employed for asphaltene precipitation modeling. At the second model, the lattice theory is introduced via the Sanchez--Lacombe equation of state (EOS). This equation of state is applied here for the first time in asphaltene precipitation modeling. The results obtained from both methods show that asphaltene precipitation during natural depletion and/or miscible gas injection can be simulated with modified FH and Sanchez-Lacombe EOS.

\section{ASPHALTENE PRECIPITATION MODEL}

Asphaltene precipitation occurs in a given range of pressure, temperature and composition in reservoir fluids. The asphaltene onset pressure locus i.e. asphaltene precipitation envelope, mainly depends on fluid nature and reservoir conditions (fluid composition, temperature and pressure) and the asphaltene content of reservoir oil. A typical asphaltene precipitation envelope is shown in Fig. 1. Experimental and theoretical phase behavior studies have shown that asphaltene precipitation starts to occur at a pressure higher than the bubble point (point A), called the upper asphaltene precipitation onset pressure, and reaches its maximum value about the bubble point pressure (Almehaideb, 2004). With as decrease in pressure down to low values, results in decrease in the amount of asphaltene precipitation. It seems that for some crude samples there is low reversibility in asphaltene precipitation; in other words, in these crudes, zero asphaltene precipitation cannot be reached at very low pressures. Theoretically, as can be seen, asphaltene precipitation stops when pressure reaches point $B$.

Thermodynamic models of asphaltene precipitation can be used to predict asphaltene precipitation conditions (point A) and the amounts of precipitated asphaltene. Generally there are about four distinct types of thermodynamic models for asphaltene precipitation prediction. Common modeling methods include (1) the solubility model, (2) the solid model, the (3) colloidal and (4) the micellization models.

The solubility models are based on the simplified Flory-Huggins polymer theory (Flory, 1942) and describe asphaltene stability in terms of reversible equilibrium solution. First, a VLE flash calculation is performed using an EOS to obtain the bulk properties and equilibrium compositions of the vapor and liquid phases. Then an LLE calculation is conducted using the Flory-Huggins theory to obtain the fraction of asphaltene component. Hirschberg et al. (1984) proposed a solubility precipitation model based on the Soave equation of state (Soave, 1972). Kawanaka et al. (1988) and Cimino et al. (1995) developed a precipitation model on the basis of polymer-solution thermodynamics. This model is believed to be a good application of the polymersolution theory, so it provides a good representation of asphaltene-phase behavior. However, it needs accurate experimental data to adjust the parameters of this model. Park and Mansoori (1988) and later Nor-Azlan and Adewumi (1993) proposed another model based on the statistical thermodynamics of polymer solutions.

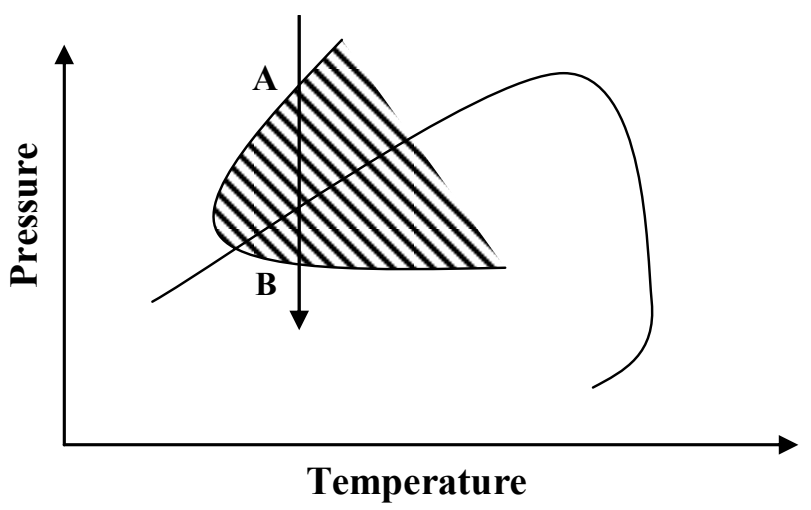

Figure 1: Asphaltene precipitation phase envelope 
Leontaritis and Mansoori (1987) proposed a thermodynamic colloidal model that is able to predict the onset of asphaltene flocculation. According to this model, asphaltenes exist in the oil as solid particles in colloidal suspension, stabilized by resins adsorbed on their surface. In this model, according to the theories of surface-chemistry, thermodynamic processing methods are applied to study the precipitation of asphaltenes. This model can reflect the real state of crude oils and is effective for asphaltenes and the molecular weights of asphaltene (Mansoori, 1997; Leontaritis, 1996).

Another theoretical model for asphaltene precipitation is the solid model. At this model asphaltenes phase is considered as a solid phase (liquid-solid equilibrium). Solid models may require many empirical parameters and excessive tuning to match experimental data (Thomas et al., 1992). Nghiem et al. (1993) proposed their model by considering the precipitated asphaltene as a pure solid dense phase; At this model the heaviest component in the oil can be splited into two parts: the nonprecipitating and precipitating components. The precipitating component is taken as asphaltene. Chung (1992) developed his precipitation model by treating asphaltene as a lumped pseudo-component (compound) and the other components as solvents. Vafaie et al. $(2003,2006)$ applied association theory to the prediction of asphaltene deposition.

The recent theoretical model of asphaltene precipitation is the asphaltene micellization model. Asphaltene aggregation/micelle core formation/ resinf adsprption onto asphaltene surface/resin shield deformation and finally micelle formation play the key role at this model.

Victorov and Firoozabadi (1996) used the principle of the Gibb's free energy minimization of to determine equilibrium composition and amount of vapor-liquid and asphaltene phases.

Regarding the theoretical models of asphaltene precipitation, it is shown that the solubility model is simpler than the solid model for application. At both models own asphaltene play the key role in precipitation, while at the colloidal and micellization models resins have the main role in precipitation.

\section{THEORY}

\section{Polymer Solution Theory Based on the Flory - Huggins Model}

Here first application of the polymer solution concept for prediction of asphaltene phase behavior is discussed and then the interaction parameter $\left(l_{12}\right)$ for the residual term of original the FH theory is introduced. Finally the modified form of the FH theory which is remodified by using Miller's combinatorial term will be introduced.

Flory (1942) developed a thermodynamic model of the lattice theory for mixtures of polymers with very large molecules and solvents with much smaller molecules. The large asphaltene molecules in oil are similar in structure and behavior to such polymer molecules. The remaining components in the oil act as the solvent in which the asphaltenes are dissolved or suspended. Hirschberg et al. (1984) used this approach to predict asphaltene solubility in oil. This model was later used by others as well (Burke et al., 1990; Kokal et al., 1992). According to this model, the solubility of asphaltene in oil is given by

$\phi_{\mathrm{a}}^{\mathrm{L}}=\exp \left[-1+\frac{v_{\mathrm{a}}}{v_{\mathrm{L}}}-\frac{v_{\mathrm{a}}}{\mathrm{RT}}\left(\delta_{\mathrm{a}}-\delta_{\mathrm{L}}\right)^{2}\right]$

This equation is derived from the original FloryHuggins polymer solution theory in which the partial molar Gibb's free energy or chemical potential of component 1 is

$\Delta \overline{\mathrm{G}}_{1}=\Delta \mu_{1}=\Delta \overline{\mathrm{H}}_{1}-\mathrm{T} \Delta \overline{\mathrm{S}}_{1}$

where $\Delta \bar{H}_{1}$ is the partial molar enthalpy which represents the residual term and $\Delta \overline{\mathrm{S}}_{1}$ is the partial molar entropy which represents the combinatorial term.

At the original FH polymer solution theory, the residual and combinatorial terms are defined as follows:

$$
\begin{aligned}
& \Delta \overline{\mathrm{H}}_{1}=v_{1}\left(\phi_{2}\right)^{2}\left(\delta_{1}-\delta_{2}\right)^{2} \\
& \Delta \overline{\mathrm{S}}_{1}=-\mathrm{R}\left[\ln \phi_{1}+\left(1-\frac{v_{1}}{v_{2}}\right) \phi_{2}\right]
\end{aligned}
$$

Here (1) and (2) are the polymer (asphaltene) and asphaltene-free solvent (oil and/or precipitant and/or solvent) respectively.

The residual term (enthalpy change of mixing) in the FH theory can be modified by introducing the pair interaction parameter $l_{12}$. In other words Eq. (3) changes to

$$
\Delta \overline{\mathrm{H}}_{1}=v_{1}\left(\phi_{2}\right)^{2}\left[\left(\delta_{1}-\delta_{2}\right)^{2}+2 \mathrm{l}_{12} \delta_{1} \delta_{2}\right]
$$


The FH combinatorial term, entropy change of mixing, can be modified by introducing the coordination number concept. After the basic theory of Flory-Huggins, many other theories have been derived. Miller [1943] derived the combinatory entropy of polymer solution by using higher order approximations for chain connectivity than that in the original Flory-Huggins theory. This improvement in the Flory-Huggins theory was identified by coordination number $z$ 's which is the number of neighbors of a central molecule in a lattice. Miller's modified theory gives essentially the same expression of combinatory entropy in polymer solution and approach to that in the Flory-Huggins theory at the limit of $z \rightarrow \infty$. Recently, Miller's theory has been used for complex polymer solutions [Saeki, 1997, 2000]:

$$
\Delta \overline{\mathrm{S}}_{1}=-\mathrm{R}\left[\ln \phi_{1}-\frac{\mathrm{z}}{2} \ln \left[1-\frac{2}{\mathrm{z}}\left(1-\frac{v_{1}}{v_{2}}\right) \phi_{2}\right]\right]
$$

where $z$ is the coordination number and has a value between 3 and 4 . In this work the coordination number is set $z=3.5$ for all samples.

Here, both pair-interaction parameter and the Miller's entropy theory have been introduced into the original FH equation. Considering these two concepts, FH partial molar Gibbs free energy is reformulated as

$$
\begin{aligned}
& \Delta \overline{\mathrm{G}}_{1}=\Delta \mu_{1}=v_{1}\left(\phi_{2}\right)^{2}\left[\left(\delta_{1}-\delta_{2}\right)^{2}+2 \mathrm{l}_{12} \delta_{1} \delta_{2}\right]+ \\
& \mathrm{RT}\left[\ln \phi_{1}-\frac{\mathrm{z}}{2} \ln \left[1-\frac{2}{\mathrm{z}}\left(1-\frac{v_{1}}{v_{2}}\right) \phi_{2}\right]\right]
\end{aligned}
$$

Rewriting Eq. (7) for asphaltene (1 or $a$ ) solubility in asphaltene-free phase ( 2 or L), the change in the chemical potential of the asphaltene fraction can be evaluated by Eq. (8):

$$
\begin{aligned}
& \Delta \mu_{\mathrm{a}}=v_{\mathrm{a}}\left(\phi_{\mathrm{L}}\right)^{2}\left[\left(\delta_{\mathrm{a}}-\delta_{\mathrm{L}}\right)^{2}+2 \mathrm{l}_{\mathrm{aL}} \delta_{\mathrm{a}} \delta_{\mathrm{L}}\right]+ \\
& \mathrm{RT}\left[\ln \phi_{\mathrm{a}}-\frac{\mathrm{z}}{2} \ln \left[1-\frac{2}{\mathrm{z}}\left(1-\frac{v_{\mathrm{a}}}{v_{\mathrm{L}}}\right) \phi_{\mathrm{L}}\right]\right]
\end{aligned}
$$

Asphaltene distribution in asphaltene-rich and asphaltene-lean phases can be monitored by equating the chemical potentials of asphaltene in the two phases in the equilibrium state:
$\Delta \mu_{\mathrm{a}}^{\mathrm{L}}=\Delta \mu_{\mathrm{a}}^{\mathrm{A}}$

Although the field observations show that the deposits contain other components besides asphaltene, it seems that under asphaltene deposition conditions, the major part of the deposits is pure asphaltene. Based on these experimental observations, it may be assumed that the precipitated phase is pure asphaltene. This assumption has been applied by different researchers. Hirschberg et al., (1984) assumed that the asphaltene phase is pure asphaltene, i.e. $\Delta \mu_{\mathrm{a}}^{\mathrm{A}}=0$.

Considering this assumption, combining equations (8) and (9) yields

$$
\begin{aligned}
& \frac{\Delta \mu_{\mathrm{a}}^{\mathrm{L}}}{\mathrm{RT}}=\frac{\mathrm{v}_{\mathrm{a}}\left(1-\phi_{\mathrm{a}}^{\mathrm{L}}\right)^{2}}{\mathrm{RT}}\left[\left(\delta_{\mathrm{a}}-\delta_{\mathrm{L}}\right)^{2}+2 \mathrm{1}_{\mathrm{aL}} \delta_{\mathrm{a}} \delta_{\mathrm{L}}\right]+ \\
& {\left[\ln \phi_{\mathrm{a}}^{\mathrm{L}}-\frac{\mathrm{z}}{2} \ln \left[1-\frac{2}{\mathrm{z}}\left(1-\frac{\mathrm{v}_{\mathrm{a}}}{\mathrm{v}_{\mathrm{L}}}\right)\left(1-\phi_{\mathrm{a}}^{\mathrm{L}}\right)\right]\right]=0}
\end{aligned}
$$

Eq. (10) can be simplified by assuming that $\phi_{\mathrm{a}}^{\mathrm{L}}<<1$, giving

$$
\phi_{\mathrm{a}}^{\mathrm{L}}=\exp \left[\begin{array}{l}
\frac{\mathrm{z}}{2} \ln \left[1-\frac{2}{\mathrm{z}}\left(1-\frac{v_{\mathrm{a}}}{v_{\mathrm{L}}}\right)\right]- \\
\frac{v_{\mathrm{a}}}{\mathrm{RT}}\left[\left(\delta_{\mathrm{a}}-\delta_{\mathrm{L}}\right)^{2}+21_{\mathrm{aL}} \delta_{\mathrm{a}} \delta_{\mathrm{L}}\right]
\end{array}\right]
$$

In this work, Eq. (11) has been used to describe asphaltene phase behavior in hydrocarbon fluids. In this work this modification is called the modified Miller-Flory-Huggings (MFH) model. Besides, by setting $1_{\mathrm{aL}}=0$ in Eq. (11) the new version of the the Miller's theory can be obtained:

$$
\phi_{\mathrm{a}}^{\mathrm{L}}=\exp \left[\begin{array}{l}
\frac{\mathrm{z}}{2} \ln \left[1-\frac{2}{\mathrm{z}}\left(1-\frac{\mathrm{v}_{\mathrm{a}}}{\mathrm{v}_{\mathrm{L}}}\right)\right]- \\
\frac{\mathrm{v}_{\mathrm{a}}}{\mathrm{RT}}\left[\left(\delta_{\mathrm{a}}-\delta_{\mathrm{L}}\right)^{2}\right]
\end{array}\right]
$$

The ability of Miller's theory to predict asphaltene precipitation from reservoir fluids was checked by using Eq. (12). Here the results obtained were denoted with "Miller" in all figures. 
Lattice Theory Based on the Sanchez-Lacombe Equation of State

The Sanchez-Lacombe (SL) equation of state is based on an extension of the classical lattice fluid theory, with vacancies in the lattice in order to account for compressibility. The SL EOS expresses the pressure $(\mathrm{P})$-volume $(1 / \widetilde{\rho})$-temperature $(\mathrm{T})$ relationship for polymer compounds, which for pure fluids is given by (Sanchez and Lacombe, 1976)

$\tilde{\rho}^{2}+\tilde{\mathrm{P}}+\tilde{\mathrm{T}}\left[\ln \left(1-\tilde{\rho}+\left(1-\frac{1}{\mathrm{r}}\right) \tilde{\rho}\right]=0\right.$

where $\tilde{\mathrm{P}}, \tilde{\mathrm{T}}$ and $\tilde{\rho}$ are respectively the reduced pressure, temperature and density and are defined by $\tilde{\mathrm{P}}=\frac{\mathrm{P}}{\mathrm{P}^{*}}, \tilde{\mathrm{T}}=\frac{\mathrm{T}}{\mathrm{T}^{*}}$ and $\tilde{\rho}=\frac{\rho}{\rho^{*}}, \rho^{*}=\frac{\mathrm{M}_{\mathrm{w}}}{\mathrm{r}^{\mathrm{o}} \mathrm{v}^{*}}$ and $\mathrm{P}^{*} \mathrm{v}^{*}=\mathrm{RT}^{*}$.

For pure components these parameters can be evaluated by using saturation data. For unknown fractions (such as plus fractions and/or asphaltene), they can be determined by regression with experimental data. To estimate the density of polymer or solvent in polymer/solvent systems, which are binary component systems, the characteristic parameters $\mathrm{P}^{*}, \mathrm{~T}^{*}, \mathrm{v}^{*}$ and $\rho^{*}$ must be determined. To extend this equation to an multicomponent mixture, it is necessary to define the characteristic mixture temperature, pressure and close-packed molar volume. Different types of mixing rules can be employed. Here the mixing rule given by Sanchez et al., (1978) is applied to calculate the characteristic parameters of the mixtures:

$$
\begin{aligned}
& \mathrm{v}^{*}=\phi_{1}^{\mathrm{o}} \mathrm{v}_{1}^{*}+\phi_{2}^{\mathrm{o}} \mathrm{v}_{2}^{*} \\
& \phi_{1}^{\mathrm{o}}=\frac{\phi_{1}}{\phi_{1}+\left(\mathrm{v}_{1}^{*} / \mathrm{v}_{2}^{*}\right) \phi_{2}} \\
& \phi_{2}^{\mathrm{o}}=1-\phi_{1}^{\mathrm{o}} \\
& \phi_{\mathrm{i}}=\frac{\mathrm{m}_{\mathrm{i}} / \rho_{\mathrm{i}}^{*}}{\mathrm{~m}_{1} / \rho_{1}^{*}+\mathrm{m}_{2} / \rho_{2}^{*}} \mathrm{i}=1,2 \\
& \phi_{1}+\phi_{2}=1 \\
& \chi_{12}=\left[\mathrm{P}_{1}^{*}+\mathrm{P}_{2}^{*}-2\left(\mathrm{P}_{1}^{*} \mathrm{P}_{2}^{*}\right)^{1 / 2}\left(1-\mathrm{k}_{12}\right)\right] \mathrm{v}_{1}^{*} / \mathrm{RT}
\end{aligned}
$$

$$
\begin{aligned}
& \mathrm{P}^{*}=\phi_{1} \mathrm{P}_{1}^{*}+\phi_{2} \mathrm{P}_{2}^{*}-\left(\mathrm{RT} / \mathrm{v}_{1}^{*}\right) \phi_{1} \phi_{2} \chi_{12} \\
& \mathrm{~T}^{*}=\mathrm{P}^{*} \mathrm{v}^{*} / \mathrm{R} \\
& \mathrm{r}_{1}=\mathrm{r}_{1}^{\mathrm{O}} \mathrm{v}_{1}^{*} / \mathrm{v}^{*} \\
& \mathrm{r}=\mathrm{x}_{1} \mathrm{r}_{1}+\mathrm{x}_{2} \mathrm{r}_{2}, \mathrm{x}_{1}+\mathrm{x}_{2}=1 \\
& 1 / \rho^{*}=\mathrm{m}_{1} / \rho_{1}^{*}+\mathrm{m}_{2} / \rho_{2}^{*}
\end{aligned}
$$

The subscript $i=1$ stands for polymer and 2 , for solvent.

The derived Sanchez-Lacombe chemical potential of component (1) in liquid phase (L) is

$$
\begin{aligned}
& \frac{\mu_{1}^{\mathrm{L}}}{\mathrm{RT}}=\ln \phi_{1}^{\mathrm{L}}+\left(1-\frac{\mathrm{r}_{1}}{\mathrm{r}_{2}}\right)\left(1-\phi_{1}^{\mathrm{L}}\right)+\mathrm{r}_{1}^{\mathrm{O}} \tilde{\rho} \times \chi_{12}\left(1-\phi_{1}^{\mathrm{L}}\right)^{2}+ \\
& {\left[-\frac{\tilde{\rho}}{\tilde{\mathrm{T}}_{1}}+\frac{\tilde{\mathrm{P}}_{1}}{\tilde{\mathrm{T}}_{1} \tilde{\rho}}+\frac{(1-\tilde{\rho}) \ln (1-\tilde{\rho})}{\tilde{\rho}}+\frac{\ln \tilde{\rho}}{\mathrm{r}_{1}^{\mathrm{o}}}\right] \mathrm{r}_{1}^{\mathrm{o}}}
\end{aligned}
$$

For pure components the chemical potential is as follows:

$\frac{\mu_{1, \text { pure }}}{\mathrm{RT}}=\left[-\frac{\tilde{\rho}_{1}}{\tilde{\mathrm{T}}_{1}}+\frac{\tilde{\mathrm{P}}_{1}}{\tilde{\mathrm{T}}_{1} \tilde{\rho}_{1}}+\frac{\left(1-\tilde{\rho}_{1}\right) \ln \left(1-\tilde{\rho}_{1}\right)}{\tilde{\rho}_{1}}+\mathrm{r}_{1}^{\mathrm{o}}\right] \mathrm{r}_{1}^{\mathrm{o}}$

In this work, the SL EOS was used in the asphaltene-oil system to predict the onset and amount of asphaltene precipitation from live and dead oils. In this system, the subscript (1) stands for asphaltene $(a)$ and subscript (2) stands for liquid $(L)$. Assuming that the asphaltene-rich phase is pure asphaltene, the equilibrium state between dissolved asphaltene in the liquid and precipitated pure asphaltene phases can be described by

$\frac{\mu_{\mathrm{a}}^{\mathrm{L}}}{\mathrm{RT}}=\frac{\mu_{\mathrm{a}, \text { pure }}}{\mathrm{RT}}$ and then

$$
\begin{aligned}
& \ln \phi_{\mathrm{a}}^{\mathrm{L}}+\left(1-\frac{\mathrm{r}_{\mathrm{a}}}{\mathrm{r}_{\mathrm{L}}}\right)\left(1-\phi_{\mathrm{a}}^{\mathrm{L}}\right)+\mathrm{r}_{\mathrm{a}}^{\mathrm{o}} \tilde{\rho} \times \chi_{\mathrm{aL}}\left(1-\phi_{\mathrm{a}}^{\mathrm{L}}\right)^{2}+ \\
& {\left[\begin{array}{l}
-\frac{\tilde{\rho}}{\tilde{\mathrm{T}}_{\mathrm{a}}}+\frac{\tilde{\mathrm{P}}_{\mathrm{a}}}{\tilde{\mathrm{T}}_{\mathrm{a}} \tilde{\rho}}+ \\
\frac{(1-\tilde{\rho}) \ln (1-\tilde{\rho})}{\tilde{\rho}}+\frac{\ln \tilde{\rho}}{\mathrm{r}_{\mathrm{a}}^{\mathrm{o}}}
\end{array}\right] \mathrm{r}_{\mathrm{a}}^{\mathrm{o}}} \\
& =\left[-\frac{\tilde{\rho}_{\mathrm{a}}}{\tilde{\mathrm{T}}_{\mathrm{a}}}+\frac{\tilde{\mathrm{P}}_{\mathrm{a}}}{\tilde{\mathrm{T}}_{\mathrm{a}} \tilde{\rho}_{\mathrm{a}}}+\frac{\left(1-\tilde{\rho}_{\mathrm{a}}\right) \ln \left(1-\tilde{\rho}_{\mathrm{a}}\right)}{\tilde{\rho}_{\mathrm{a}}}+\mathrm{r}_{\mathrm{a}}^{\mathrm{o}}\right] \mathrm{r}_{\mathrm{a}}^{\mathrm{o}}
\end{aligned}
$$




\section{COMPOSITIONAL ANALYSIS AND PRECIPITATION DATA ON THE SAMPLES}

Table 1 containes the compositions and basic fluid properties of the three oil samples used in this work. Sample 1 is taken from the paper published by Hirschberg et al. (1984). This sample is the Iranian tank oil with an n-pentane asphaltene content of $3.9 \%$ wt. Sample 2, reported by Burke et al. (1990), is a live reservoir fluid and contains $16.8 \% \mathrm{wt}$ asphaltene under stock tank conditions. This has a bubble point of $20.4 \mathrm{MPa}$ (2950 psia) and a reservoir temperature of $100^{\circ} \mathrm{C}$. Sample 3 is an Iranian live oil which its reservoir temperature is $96.11^{\circ} \mathrm{C}$ and saturation pressure is $13.1 \mathrm{MPa}$ (1905 psia). The asphaltene content of this oil under stock tank conditions is $6.64 \%$ wt.

To illustrate the application of the proposed models to asphaltene precipitation, experimental data from three oil samples are used. The experimental values of asphaltene precipitation from tank oil (sample 1) through titration with n-pentane are shown in Table 2. The asphaltene precipitation data from sample 2 at $100^{\circ} \mathrm{C}$ are shown in Table 3. The amounts of precipitates that are formed and deposited from the live oil and the asphaltene content of the residual stock-tank oil are reported here. The asphaltene precipitates from live oil sample 3 at different pressures and a temperature of $96.11^{\circ} \mathrm{C}$ are given in Table 4.

Table 1: Compositions (mol\%) and properties of oils used in the study

\begin{tabular}{|c|c|c|c|}
\hline & \multicolumn{2}{|c|}{ Mole\% } \\
\hline Component & Sample 1 & Sample 2 & Sample 3 \\
\hline N2 & 0.000 & 0.570 & 0.270 \\
H2S & 0.000 & 0.000 & 0.030 \\
CO2 & 0.000 & 2.460 & 30.440 \\
C1 & 0.100 & 36.370 & 7.920 \\
C2 & 0.480 & 3.470 & 5.530 \\
C3 & 2.050 & 4.050 & 0.870 \\
IC4 & 0.880 & 0.590 & 2.510 \\
NC4 & 3.160 & 1.340 & 1.030 \\
IC5 & 1.930 & 0.740 & 1.490 \\
NC5 & 2.580 & 0.830 & 7.430 \\
C7+ & 4.320 & 1.620 & 40.820 \\
\hline C7+ M & 84.500 & 47.960 & 289.220 \\
C7+ SG & 221.500 & 329.000 & 0.920 \\
Asphaltene \%wt & 0.873 & 0.959 & 6.640 \\
\hline
\end{tabular}

Table 2: Tank oil (sample 1) titration data $\left(24^{\circ} \mathrm{C}\right.$ and $\left.100 \mathrm{kPa}\right)$

\begin{tabular}{|c|c|}
\hline $\begin{array}{c}\text { Dilution ratio } \\
\left(\mathbf{c m}^{\mathbf{3}} \mathbf{n}-\mathbf{C 5} / \mathbf{g} \text { tank oil) }\right.\end{array}$ & $\begin{array}{c}\text { Asphaltene precipitation } \\
\text { (\%w) }\end{array}$ \\
\hline 10 & 3.610 \\
20 & 3.790 \\
50 & 3.870 \\
\hline
\end{tabular}

Table 3: Asphaltene precipitation from sample 2 at $100^{\circ} \mathrm{C}$ as a function of pressure

\begin{tabular}{|c|c|c|}
\hline $\begin{array}{c}\text { Test pressure } \\
\text { (MPa) }\end{array}$ & $\begin{array}{c}\text { Asphaltene precipitation } \\
\text { (\%wt) }\end{array}$ & $\begin{array}{c}\text { Precipitates remaining in residual } \\
\text { stock-tank oil (\%wt) }\end{array}$ \\
\hline 6.996 & 0.403 & 15.730 \\
13.891 & 1.037 & 14.980 \\
20.924 & 0.742 & 15.060 \\
27.680 & 0.402 & 14.860 \\
\hline
\end{tabular}

Table 4: Asphaltene precipitation from sample 3 at $96.11^{\circ} \mathrm{C}$ as a function of pressure

\begin{tabular}{|c|c|}
\hline Test pressure (MPa) & Asphaltene precipitation (\%wt) \\
\hline 10.342 & 0.0217 \\
13.100 & 0.0600 \\
17.237 & 0.0552 \\
31.026 & 0.0420 \\
37.921 & 0.0042 \\
\hline
\end{tabular}




\section{RESULTS AND DISCUSSION}

In this work, the two mentioned models are used for asphaltene precipitation modeling. Volume fractions of dissolved asphaltene in crude oil samples under given conditions using the FH, MFH, Miller and SL EOS models can be calculated by Eqs. (1), (11), (12) and (27) respectively. As can be seen in these equations, there are some adjustable parameters that should be determined by using some experimental data. The adjustable parameters are determined as follows. The experimental weight fraction of precipitated asphaltene is first converted into volume fraction; the objective function is then defined as the difference between experimental and calculated amounts of asphaltene precipitation. The objective function is minimized by the "fminsearch" function in MATLAB software. Adjusted values of parameters from the FH, MFH, Miller and SL EOS models for three oil samples are given in Tables 5 to 8 . The adjusted parameters are used in asphaltene precipitation modeling in the three oil samples.

The modeling results on amount of asphaltene precipitation vs. volume of n-pentane added to tank oil (sample 1) are given in Fig. 2. This figure shows that the simple FH model is not able to predict the amount of asphaltene precipitation in this sample. However, the FH model modified by introduction of Miller's theory and binary interaction (MFH and Miller models) shows improvement over the original and the modified FH and is able to simulate the precipitation more properly.

It can be observed in Fig. 2 that the results of the Sanchez-Lacombe EOS model for asphaltene precipitation in sample 1. As it can be seen, the modeling results are in very good agreement with the experimental data.

Table 5: Adjusted parameters of the FH model

\begin{tabular}{|c|c|c|}
\hline Samples & $\begin{array}{c}\delta_{\mathrm{a}} \\
(\mathbf{M P a})^{\mathbf{0 . 5}}\end{array}$ & $\begin{array}{c}\mathrm{v}_{\mathrm{a}} \\
\left(\mathbf{c m}^{\mathbf{3}} / \mathbf{m o l}_{\mathbf{~}}\right.\end{array}$ \\
\hline 1 & 18.6879 & 645.8921 \\
2 & 26.3310 & 174.0292 \\
3 & 18.4736 & 3619.7465 \\
\hline
\end{tabular}

Table 6:Adjusted parameters of the MFH model

\begin{tabular}{|c|c|c|c|}
\hline Samples & $\begin{array}{c}\delta_{\mathrm{a}} \\
(\mathbf{M P a})^{\mathbf{0 . 5}}\end{array}$ & $\begin{array}{c}\mathrm{v}_{\mathrm{a}} \\
\left.\mathbf{( c m}^{\mathbf{3}} \mathbf{m o l}\right)\end{array}$ & $1_{\mathrm{aL}}$ \\
\hline 1 & 19.9231 & 1067.025 & -0.0053 \\
2 & 22.4171 & 237.0458 & 0.0400 \\
3 (3-exp. points) & 20.2139 & 2484.742 & -0.0396 \\
3 (5-exp. points) & 19.0963 & 1843.938 & -0.0175 \\
\hline
\end{tabular}

Table 7: Adjusted parameters of the Miller's model

\begin{tabular}{|c|c|c|c|}
\hline Samples & $\begin{array}{c}\delta_{\mathrm{a}} \\
(\mathbf{M P a})^{\mathbf{0 . 5}}\end{array}$ & $\begin{array}{c}\mathrm{v}_{\mathrm{a}} \\
\mathbf{( c m}^{\mathbf{3} / \mathbf{m o l})}\end{array}$ & $1_{\mathrm{aL}}$ \\
\hline 1 & 19.5660 & 1068.5223 & 0.0000 \\
2 & 26.0853 & 120.1211 & 0.0000 \\
3 (3-exp. points) & 17.0071 & 3683.3562 & 0.0000 \\
3 (5-exp. points) & 17.2791 & 2778.1246 & 0.0000 \\
\hline
\end{tabular}

Table 8: Adjusted parameters of the SL EOS

\begin{tabular}{|c|c|c|c|c|c|c|c|}
\hline Samples & $\begin{array}{c}\mathrm{P}^{*} \\
\text { (MPa) } \\
\text { Asph. }\end{array}$ & $\begin{array}{c}\mathrm{T}^{*} \\
(\mathbf{K}) \\
\text { Asph. }\end{array}$ & $\begin{array}{c}\rho^{*} \\
\left(\mathrm{~cm}^{3} / \mathrm{gr}\right) \\
\text { Asph. }\end{array}$ & $\begin{array}{c}\mathrm{P}^{*} \\
(\mathbf{M P a}) \\
\mathbf{C 7}^{+}\end{array}$ & $\begin{array}{c}\mathrm{T}^{*} \\
\mathbf{( K )} \\
\mathbf{C} 7^{+} \\
\end{array}$ & $\begin{array}{c}\rho^{*} \\
\left(\mathrm{~cm}^{3} / \mathrm{gr}\right) \\
\mathrm{C}^{+}\end{array}$ & $\mathrm{k}_{12}$ \\
\hline 1 & 443.5261 & 663.9 & 1.20 & 423.6485 & 364.5 & 0.4884 & 0.040 \\
\hline 2 (4-exp.points) & 375.9713 & 489.6 & 1.30 & 211.1244 & 433.5 & 1.52 & 0.040 \\
\hline 2 (3-exp.points) & 170.7556 & 648.6 & 1.32 & 235.2906 & 576.5 & 1.41 & 0.040 \\
\hline 3 (3-exp.points) & 918.106 & 291.4 & 2.10 & 342.6765 & 488.7 & 0.9212 & -0.026 \\
\hline 3 (5-exp.points) & 542.3763 & 426.0 & 1.33 & 452.1928 & 313.1 & 1.76 & 0.035 \\
\hline
\end{tabular}




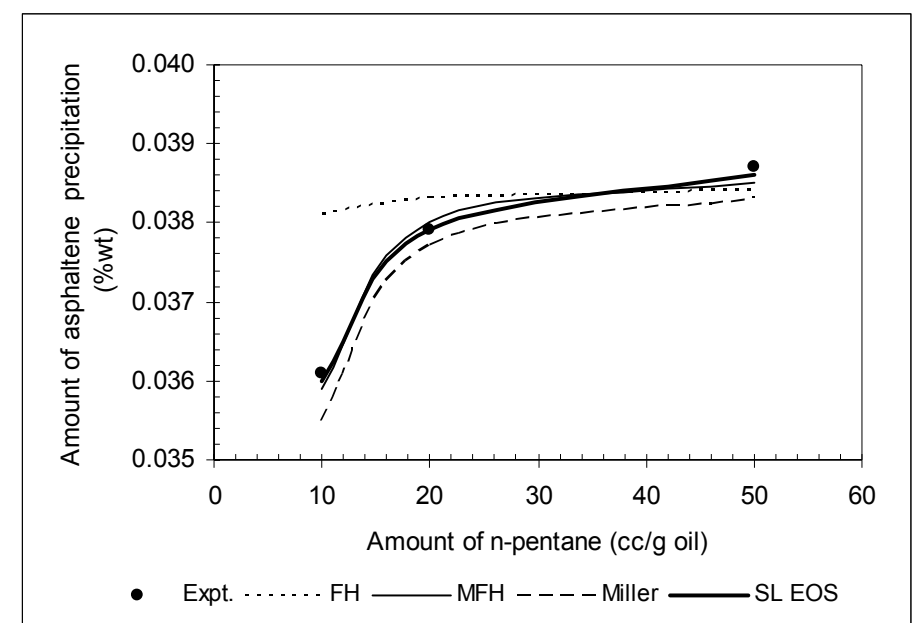

Figure 2: Prediction of amount of asphaltene precipitation from sample 1 vs. volume of n-pentane at $24^{\circ} \mathrm{C}$ and $100 \mathrm{kPa}$ - all models

Fig. 3 contains the results of the simple FH, MFH, Miller and SL EOS models for oil sample 2. This figure shows the effect of pressure on the amount of asphaltene precipitation in a live oil sample. Based on the theoretical and experimental observations, reduction in pressure from reservoir pressure down to saturation pressure causes an increase in the amounts of asphaltene precipitation. A further decrease in pressure from saturation to low pressure, however, results in a decrease in amount of asphaltene formation. The saturation pressure for sample 2 is about $20.4 \mathrm{MPa}$. In other words, maximum precipitation should be at about this pressure; however, as can be seen in Fig. 3, the experimental data for this sample do not support this fact. Fig. 3 comprises results from different models used in this work. The true precipitation trend for this sample is predicted by the FH model but this model is not able to quantitatively model amount of asphaltene in this sample and its results are very poor compared to those of the other models. As this figure shows, the results of the MFH and Miller's models are better than those of the simple FH model. These models show maximum precipitation at about bubble-point pressure; their quantitative results are also better than the simple FH model.

The first run of the SL EOS model for sample 2 is based on four experimental data points (Fig. 3 - "SL EOS-1"). These do not show maximum precipitation around the bubble-point pressure of the sample. Although the results of the SL EOS-1 model are in good agreement with the experimental data, it seems that the experimental results are not what are expected in practice. The second run of the SL EOS model on sample 2 is shown as "SL EOS-2" in Fig. 3. This run is based on three experimental data points, which seem to be correct. As shown in this figure, the results of the second run show the correct trend from the maximum precipitation point of view and its results are quantitatively in good agreement with experimental ones. Two runs of the SL EOS model for sample 2 are depicted separately in Fig. 4. As this figure shows, the precipitation trend in the second one is ("SL EOS-2") completely in agreement with theoretical and experimental data (maximum precipitation is about the bubble-point pressure).

Sample 3 has a saturation pressure of about 13.1 MPa. Two runs were conducted for this sample. In the first run only three experimental data (single phase region) were considered. In Fig. 5 the capability of the three models in predicting asphaltene precipitation for sample 3 in the first run is shown. As in the case of the two previous samples, the prediction for this sample by the $\mathrm{FH}$ model is not accurate, while the MFH, Miller and SL EOS models forecast the asphaltene precipitation data accurately. In the next run for sample 3, all five experimental data points, including the ones above and below saturation point pressure, are used in the regression. The simple FH model does not converge in this case. So the calculated results from only the MFH, Miller and SL EOS models are compared in Fig. 6. The obtained results show that the predictions of the MFH, Miller and SL EOS models show the correct trend in asphaltene precipitation and that the results from the SL EOS model are in good agreement with the experimental data. 


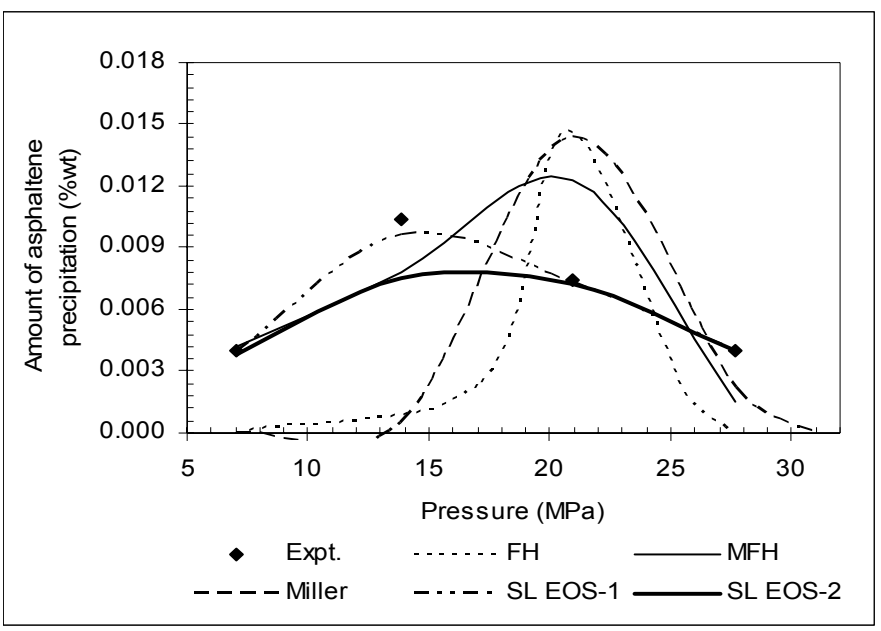

Figure 3: Prediction of amount of asphaltene precipitation from sample 2 vs. pressure at $100^{\circ} \mathrm{C}-$ all models

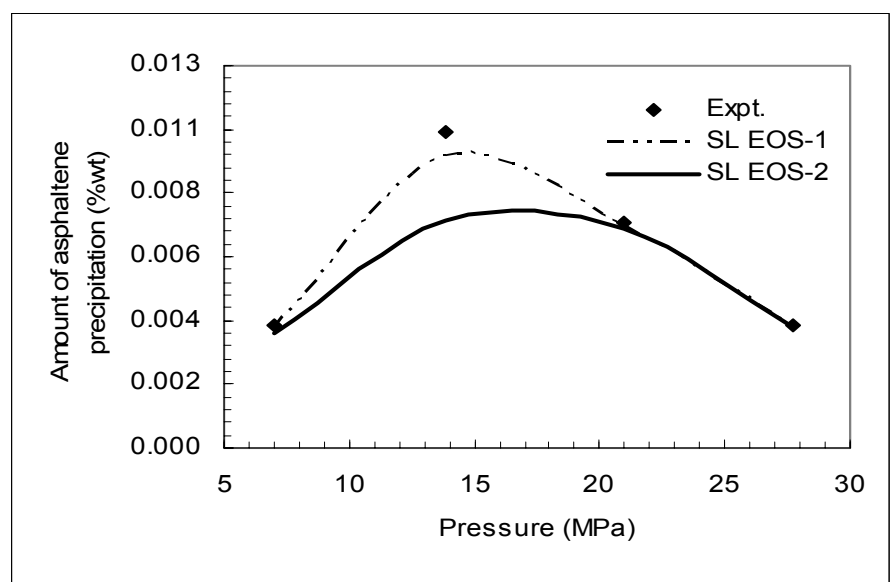

Figure 4: Prediction of amount of asphaltene precipitation from sample 2 vs. pressure at $100^{\circ} \mathrm{C}$

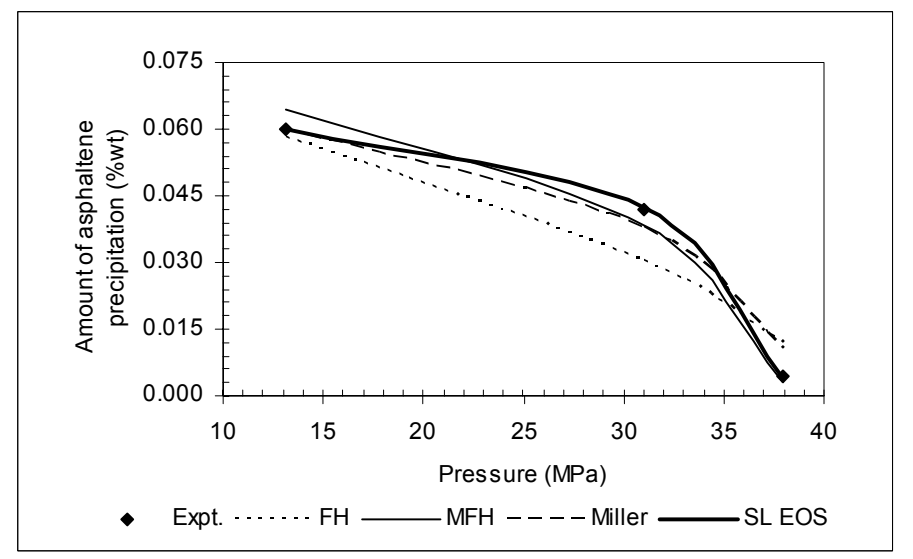

Figure 5: Prediction of amount of asphaltene precipitation from sample 3 vs. pressure at $96.11^{\circ} \mathrm{C}-$ all models 


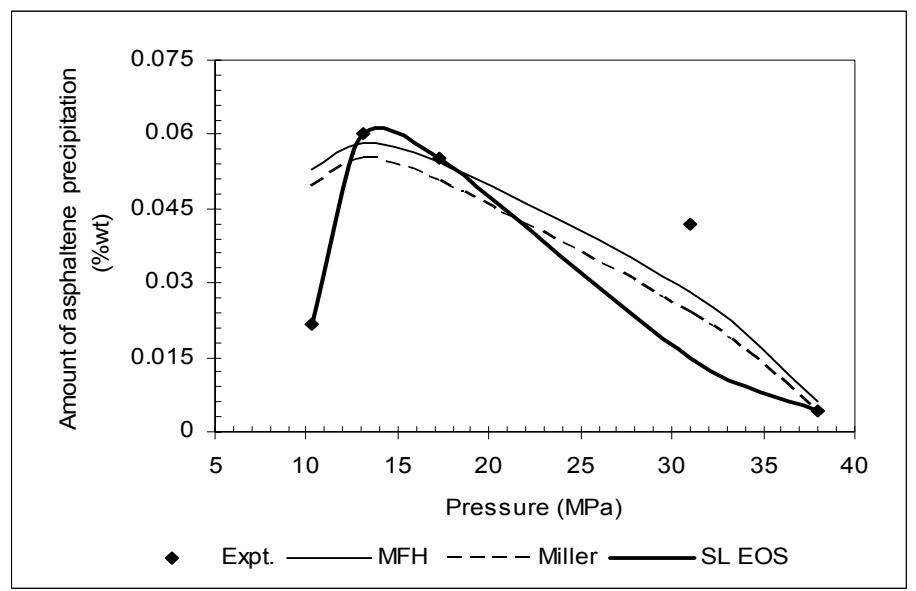

Figure 6: Prediction of amount of asphaltene precipitation from sample 3 vs. pressure at $96.11^{\circ} \mathrm{C}-$ two new models

\section{CONCLUSIONS}

Here two new methods based on the polymer solution and lattice theories were developed for modeling of asphaltene precipitation during natural depletion and/or miscible gas injection. The first method involves modification of the enthalpy and entropy terms in the simple FH theory and the second one is an application of the well-known Sanchez-Lacombe EOS for asphaltene phase behavior. Based on the modeling results in this work, the performance of both proposed models are seen to be in good agreements with the experimental data.

The simple FH theory is unable to match the experimental precipitation data quantitatively; however the introduction of Miller's combinatorial term along with the binary interaction parameter in the enthalpy term of the simple $\mathrm{FH}$ theory brings about remarkable improvement. Also, the results demonstrate that between the two newly developed models, the SL EOS model seems to be considerably more accurate than the other model.

The results obtained in this work show that provided that the experimental data are available, asphaltene precipitation in petroleum mixtures (during different natural and/or artificial processes) can be properly forecast by the modified FH theory or the Sanchez-Lacombe EOS (which are based on polymer solution or lattice theory).

\section{ACKNOWLEDGEMENTS}

The authors thank Professor G. A. Mansoori, Chemical Engineering Department, University of Illinois, 810s Clinton Street, Chicago, IL 606077000, USA and Mr. Mohabbat Ahmady, University of Austin, Texas for their support in the preparation of this article.

\section{NOMENCLATURE}

$\bar{H} \quad$ partial molar enthalpy $\quad \mathrm{J} /$ mole

$k_{12} \quad$ binary interaction parameter dimensionless

$l_{12} \quad$ pair interaction parameter dimensionless

$M_{w} \quad$ average molecular weight $\quad \mathrm{g} / \mathrm{mole}$

$m$ weight fraction dimensionless

$\mathrm{P} \quad$ pressure $\mathrm{kPa}$

$R \quad$ gas constant $\quad 8.314$

$\mathrm{J} /$ mole.K

$r^{o} \quad$ size parameter dimensionless

$\bar{S} \quad$ partial molar entropy J/mole

SG specific gravity dimensionless

$\mathrm{T}$ absolute temperature $\mathrm{K}$

$x$ mole fraction dimensionless

$v$ molar volume $\mathrm{cm} 3 /$ mole

$z \quad$ coordination number dimensionless

\section{Greek Letters}

$\begin{array}{llr}\mu & \text { chemical potential } & \text { dimensionless } \\ \rho & \text { Density } & \mathrm{g} / \mathrm{cm}^{3} \\ \delta & \text { solubility parameter } & (\mathrm{MPa})^{0.5} \\ \phi & \text { volume fraction } & \text { dimensionless }\end{array}$

\section{Subscripts and Superscripts}

* $\quad$ characteristic parameter

$\sim \quad$ reduced parameter 
1

2 solvent

A asphaltene

A asphaltene-rich phase

I i-th component

L liquid (solvent)-rich phase

\section{REFERENCES}

Almehaideb, R. A., Asphaltene precipitation and deposition in the near wellbore region: A modeling approach, Journal of Petroleum Science and Engineering 42, 157- 170 (2004).

Andersen, S. I. and Birdi, K. S.: "Aggregation of Asphaltenes as Determined by Calorimetry," J. Colloid and Interface Sci., (1991), 142, 497-502

Andersen, S. I., Speight, J. G., Observations on the critical micelle concentration of asphaltenes, Fuel 72, 1343 (1993).

Burke, N. E., Hobbs, R. E. and Kashou, S. F., Measurement and modeling of asphaltene precipitation, J. Pet. Tech. 1440 (1990).

Chung, T. H., Thermodynamic modeling for organic solid precipitation, presented at the 1992 SPE Annual Technical Conference and Exhibition, Washington, DC, Oct 4-7, 1992, paper SPE 24851 (1992).

Cimino, R., Correra S. and Sacomani P.A., Thermodynamic modelling for prediction of asphaltene deposition in live oil, presented at the 1995 SPE International Symposium on Oilfield Chemistry, San Antonio, TX, Feb 14-17, 1995, paper SPE 28993, (1995).

Flory, P. J., Thermodynamics of high polymer solutions, J. Chem. Phys. 10, 51 (1942).

Hirschberg, A., Dejong, L.N.J., Schnipper, B.A. and Meijer, J. G., "Influence of temperature and pressure on asphaltene flocculation," Soc. Pet. Eng. J. June, 283 (1984).

Kawanaka, S., Park, S. J. and Mansoori, G. A., The role of asphaltene deposition in EOR gas flooding, presented at the 1988 SPE/DOE Symposium on Enhanced Oil Recovery, Richardson, TX, Feb 15-17, 1988, paper SPE 17376 (1988).

Kokal, S. L., Najman, J., Sayegh, S. G. and George, A. E., Measurement and correlation of asphaltene precipitation from heavy oils by gas injection, J. Can. Petrol. Technol. 31, 24 (1992).

Leontaritis, K. J., Asphaltene near-wellbore formation damage modeling, presented at the 1998 SPE Formation Damage Control
Conference held in Lafayette, Louisiana, February 18-19, 1998, SPE 39446, (1998).

Leontaritis, K.J., The asphaltene and wax deposition envelops, Fuel Science and Technology Int' L. 14, 13 (1996).

Leontaritis, K. J. and Mansoori G. A., Asphaltene flocculation during oil recovery and processing: A thermodynamic-colloidal model, Proceedings of the SPE Symposium on Oil Field Chemistry, Society of Petroleum Engineers, Richardson, TX, SPE 16258 (1987).

Mansoori, G. A., Modeling of asphaltene and other heavy organic depositions, Journal of Petroleum Science and Engineering 17, 101 (1997).

Mousavi-Dehghani, S. A, Riazi, M. R., Vafaie-Sefti, M. and Mansoori, G. A., An analysis of methods for determination of onsets of asphaltene phase separations, Journal of Petroleum Science and Engineering 42, 145-156 (2004).

Miller, A. R., Proc. Cambridge Philos. Soc. 39, 54 (1943).

Mushrush, G. W. and Speight, J. M., Petroleum products: Instability and incompatibility, London: Taylor \& Francis (1995).

Nghiem, L. X., Hassam M. S. and Nutakki R., Efficient modeling of asphaltene precipitation, presented at the 1993 SPE Annual Technical Conference and Exhibition, Houston, TX, Oct 36, 1993, paper SPE 26642 (1993).

Nor-Azlan, N. and Adewumi, M. A., Development of asphaltene phase equilibrium predictive model, presented at the 1993 SPE Eastern Regional Conference and Exhibition, Pittsburgh, PA, Nov 2-4, 1993, paper SPE 26905 (1993).

Park, S. J. and Mansoori, G. A., Organic deposition from heavy petroleum crude, Proceedings of the UNITAR/UNDP 4th International Conference on Heavy Crudes and Tar Sands, Edmonton, Alberta; Aug (1988).

Saeki, S., Calculation of combinatory entropy in complex polymer solutions based on the FloryHuggins theory, Fluid Phase Equilibria136,79 (1997).

Saeki, S., Combinatory entropy in complex polymer solutions, Polymer, 41, 8331-8338 (2000).

Sanchez, I. C. and Lacombe, R. H., An elementary molecular theory of classical fluids- Pure fluids, J. Phys. Chem. 80, 2352-2361 (1976).

Sanchez, I. C. and Lacombe, R. H., Statistical thermodynamics of polymer solutions, Macromolecules 11, 1145-1156 (1978).

Sheu, E. Y., DeTar M. M., Storm, D. A., DeCanio, S. J., Aggregation and kinetics of asphahenes in 
organic solvents, Fuel 71, 299 (1992a).

Soave, G., Equilibrium constants from a modified Redlich-Kwong equation of state, Chem. Eng. Sci. 27, 1197 (1972).

Speight, J. G., The Chemistry and Technology of Petroleum, $2^{\text {nd }}$ ed. New York, Marcel Dekker (1991).

Speight, J. G., The molecular nature of petroleum asphaltenes, Arab. J. Sci. Eng. 19, 335 (1994).

Sun, S.F., Physical chemistry of macromolecules Basic principles and issues, $2^{\text {nd }}$ edn. Hoboken, New Jersey: John Wiley \& Sons, Inc., (2004).

Thomas, F. B., Bennion, D. B., Bennion, D. W. and Hunter, B. E., Efficient modeling of asphaltene precipitation, J. Can. Pet. Technol. 31, 22 (1992).

Vafaie-Sefti, M. and Mousavi-Dehghani, S.A., Application of association theory to the prediction of asphaltene deposition: Deposition due to natural depletion and miscible gas injection processes in petroleum reservoirs, Fluid Phase Equilibria 247, 182-189 (2006).

Vafaie-Sefti, M., Mousavi-Dehghani, S. A. and Mohammad-Zadeh, M., A simple model for asphaltene deposition in petroleum mixtures, Fluid Phase Equilibria. 206, 1-11 (2003).

Victorov, A. I. and Firoozabadi, A., Thermodynamic micellization model of asphaltene precipitation from petroleum fluids, AIChE Journal 42, 1753 (1996). 